Special Issue of the 8th International Advances in Applied Physics and Materials Science Congress (APMAS 2018)

\title{
The Effect of Brazing Temperature on Shear Strength of Nickel Based Superalloy (Inconel 738LC) Joints
}

\author{
S. Khathem ${ }^{a}$, M. Mohammed ${ }^{a, *}$ And F. HAShim ${ }^{b}$ \\ ${ }^{a}$ University of Technology, Department of Applied Sciences, Baghdad, Iraq \\ ${ }^{b}$ University of Technology, Department of Materials Engineering, Baghdad, Iraq
}

\begin{abstract}
In this study, nickel based superalloy In738 LC was brazed by using (Ni-Ti) and (Ni-Ti-Al) alloys which are an active filler alloys under protective atmosphere (using a high purity 99.999 Argon gas). Five brazing temperatures $\left(1135,1025,985,825,725^{\circ} \mathrm{C}\right)$ were chosen based on the solidus temperature of $(\mathrm{Ni}-\mathrm{Ti})$ and $(\mathrm{Ni}-\mathrm{Al})$ filler alloys in order to investigate the effects of these temperatures on the performance of the brazed joints. Brazing processes were carried out over $15 \mathrm{~min}$ period of time to ensure that the filler alloys were melted completely. The performance of brazing process was evaluated in terms of bonding strength by shear test. The results revealed that a maximum value of shear strength $(29 \mathrm{MPa})$ as compared with other temperatures was obtained at brazing temperature $985^{\circ} \mathrm{C}$. It was observed that the highest shear strength was influenced by the formation of Ni3Ti phase.
\end{abstract}

DOI: 10.12693/APhysPolA.135.919

PACS/topics: brazing, active filler alloy, brazing temperatures, nickel based super-alloy, shear strength

\section{Introduction}

The brazing process is applied to join two materials (similar or dissimilar) using heat and filler metals which have a melting temperature of above $\left(450^{\circ} \mathrm{C}\right)$ [1]. The joining of two materials made by heating up them to melting point of the filler metal order to ensure that molten filler flows between the two mating surface via capillary action [2]. Nickel based superalloy are unusual class of metallic material with exceptional combination of high temperature strength, toughness, and resistance to degradation in corrosive or oxidizing environments $[3,4]$. These materials are widely used in aircraft and power generation turbines, rocket engines, and other power and chemical processing plant [4]. The research focused on joining of similar material (nickel based superalloy) by using $(\mathrm{Ni}-\mathrm{Ti})$ and $(\mathrm{Ni}-\mathrm{Ti}-\mathrm{Al})$ active filler metal alloy with different concentration and different temperature at constant time, and studying the effect of temperatures on the shear strength of the joints.

\section{Experimental procedure}

The samples extracted from first stage gas turbine blade, made of nickel based superalloy, were prepared by cut at the root of the blade by wire saw to cubic dimension of $(10 \times 10 \times 10) \mathrm{mm}^{3}$. The brazing process were carried out in an electrical furnace under protective atmosphere (high purity argon gas $(99.999 \%)$ to ensure that the brazed samples are free from undesirable contaminants between the mating materials. The paste filler metals were prepared by weighting a suitable amount of metal powder alloy and mixed with drops of glycerin to

\footnotetext{
*corresponding author; e-mail: dr_mothaffer@yahoo.com
}

form a filler metal paste which in suitable for one joint. Filler alloy type, composition and brazing temperature are shown in Table I. Shear test were carried out in Laree Technology universal tensile test machine, with cross head speed of $1 \mathrm{~mm} / \mathrm{min}$ to perform the single brazing shear test at room temperature. Special fixture was prepared and used to convert the applied tensile stress to a pure shear stress in the bond line. The whole sample surface were ground and the edges were chamfered before test to avoid stress concentration.

Active filler metals alloy specification.

TABLE I

\begin{tabular}{|c|c|c|c|c|c|}
\hline \multirow{2}{*}{$\begin{array}{l}\text { Filler } \\
\text { type }\end{array}$} & \multirow{2}{*}{ Designation } & \multicolumn{3}{|c|}{ Content [wt\%] } & \multirow{2}{*}{$\begin{array}{c}\text { Brazing } \\
\text { temp. }\left[{ }^{\circ} \mathrm{C}\right]\end{array}$} \\
\hline & & $\mathrm{Ni}$ & $\mathrm{Ti}$ & $\mathrm{Al}$ & \\
\hline F1 & $65 \mathrm{Ni} 35 \mathrm{Ti}$ & 65 & 35 & - & 1135 \\
\hline F2 & $35 \mathrm{Ni} 65 \mathrm{Ti}$ & 35 & 65 & - & 1025 \\
\hline F3 & $28 \mathrm{Ni} 72 \mathrm{Ti}$ & 28 & 72 & - & 985 \\
\hline F4-a & $5 \mathrm{Ni} 5 \mathrm{Ti} 90 \mathrm{Al}$ & 5 & 5 & 90 & 825 \\
\hline F4-b & 5Ni5Ti90Al & 5 & 5 & 90 & 725 \\
\hline
\end{tabular}

\section{Results and discussion}

The microstructure analysis was achieved in order to investigate the phases which were formed during the brazing process, in this study we used SEM to study the microstructure of the joints. A typical brazing joint consists of three zones: (I) substrate zone, (II) diffusion zone, and (III) bonding zone: Athermally solidified zone was formed due to residual liquid solidifies in the joint during the cooling of the sample to the room temperature. The solidification of this zone seems to be like:

1. seam matrix, as in case of joint which bonded by F3 as shown in Fig. 1c; 

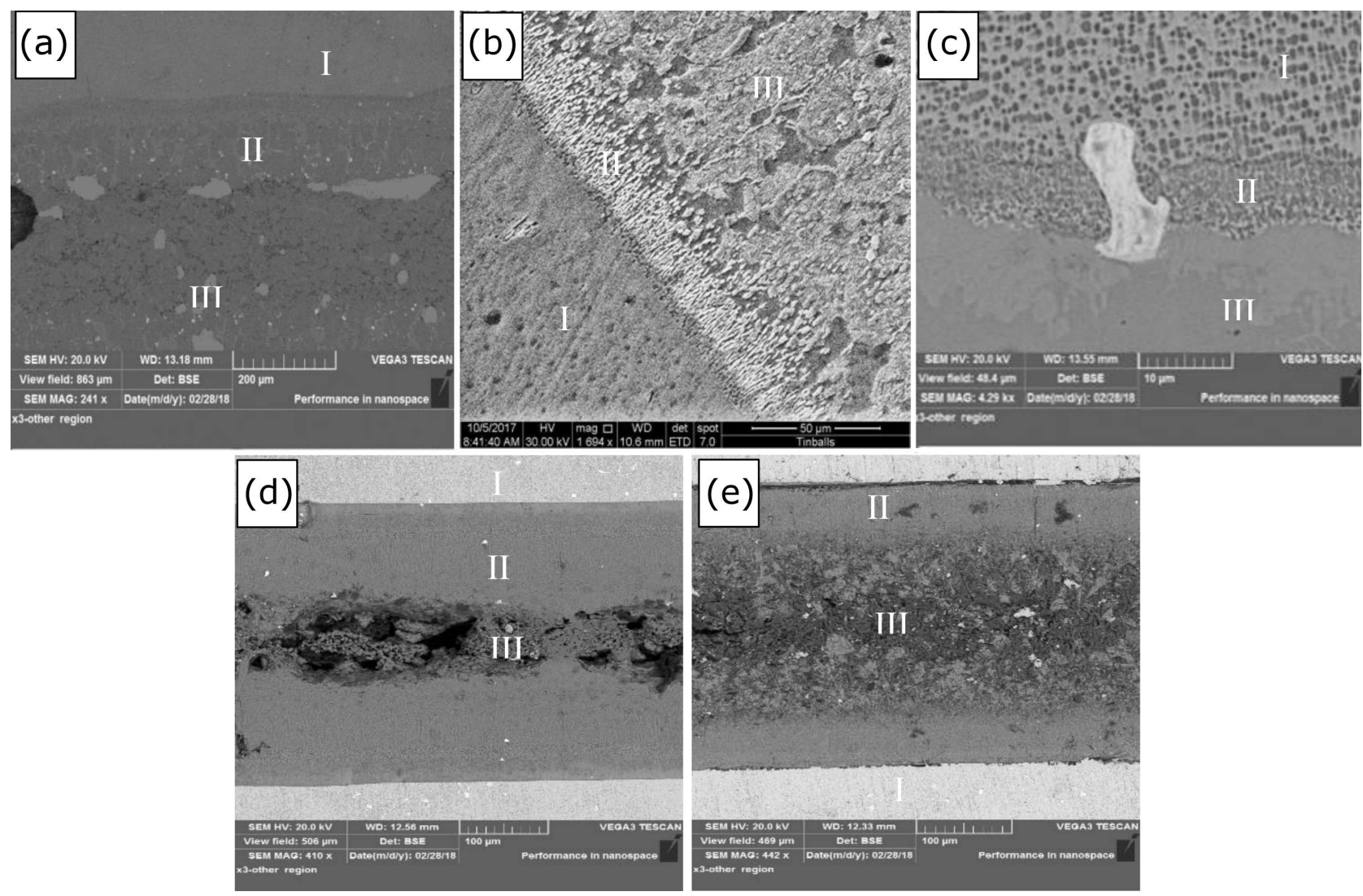

Fig. 1. SEM image of microstructure for sample bonded by (a) F1 (241×), (b) F2 (1694×), (c) F3 (429×), (d) F4-a $(410 \times)$, and $(\mathrm{e}) \mathrm{F} 4-\mathrm{b}(442 \times)$.

2. dark blocky shaped discontinuous morphology, which is formed from supersaturated phases, as well as gradually pushed to the center area of the brazed joint to form phases rich with filler elements embedded in the matrix. We can observed the variation in the distribution of these blocky phases through the microstructure as a random distribution across the enter the microstructure of bond, as in case of joints bonded by F1, F2, F4-a and F4-b as shown in Fig. 1a, b, d and e;

3 . for the samples bonded by F4, there are intermetallic and centerline eutectic constituents in the center of brazing seam.

The results of the shear was $9.3,7.33,29,15$, and 17, for the samples bonded by F1, F2, F3, F4-a and F4-b, respectively, as shown in Fig. 2. The best results was achieved by the sample bonded by $28 \%$ Ni72Ti (F3), it was about $29 \mathrm{MPa}$, as a results of strong bond between the base metal and filler alloy, as compared with the other joints. The reaction layers that crossed in the center of the brazing area become globules and discontinuous for sample bonded by F1 and F2. This suggests that the continuous reaction layer played an important role to increase the shear strength of the brazed joint as in case of joint bonded by F3, it can be clearly observed that the formation of the reaction layer occurred continuously

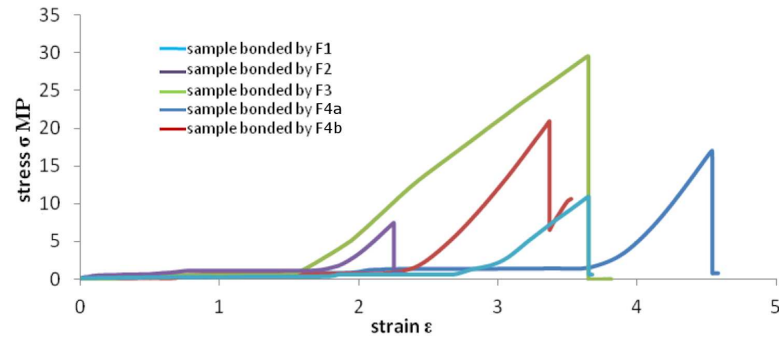

Fig. 2. Stress-Strain curves during shear test on tensile machine.

in close proximity to the In $738 \mathrm{LC}$ side zone compared to the center zone of the brazing area. It well known that the reaction layer (DAZ) influence the strength of the brazed joint. The weakest area was located at the center of the brazed zone during shearing which was Tirich phases.

\section{Conclusion}

1. The highest shear strength of $29 \mathrm{MPa}$, as compared with other samples, was obtained at a brazing temperature $985^{\circ} \mathrm{C}$. 
2. Athermally solidified zone was formed due to residual liquid solidification in the joint during the cooling of the sample to the room temperature. The solidification of this zone seems to be like: a seam matrix as in case of joint which bonded by F3 or as a dark blocky shaped discontinuous morphology which is formed from supersaturated phases, as well as gradually pushed to the center area of the brazed joint to form phases rich with filler elements embedded in the matrix, as in case of joints bonded by $\mathrm{F} 1, \mathrm{~F} 2$ and F4.

3. For the samples bonded by F4-a, there were intermetallic and centerline eutectic constituents in the center of brazing seam. That complex intermetallic was formed due to lack of diffusion at brazing temperature of $825^{\circ} \mathrm{C}$.
4. The formation of two reaction layers crossing the center of the brazing area needs occurring the diffusion between the base metal elements and the molten filler metals as in the case of F3 brazed joint.

\section{References}

[1] G.Humptson, D.M. Jacobson, Principles of soldering and brazing, ASM International, USA 1994.

[2] A. Rabinkin, Brazing Filler Metals in: Encyclopedia of Materials Science and Technology, Elsevier Science, 2002.

[3] J. Muhanned, M.Sc. Thesis, Middle Technical University, Engeneering Technical College, 2017.

[4] R. Reed, The superalloys, 1st ed., Cambridge University Press, UK 2006. 